\title{
A RANKING OF THE MOST KNOWN FREEWARE AND OPEN SOURCE DISCRETE- EVENT SIMULATION TOOLS
}

\author{
António A.C. Vieira ${ }^{(a)}$, Luís M.S. Dias ${ }^{(b)}$, Maribel Y. Santos ${ }^{(c)}$ Guilherme A.B. Pereira $^{(\mathrm{d})}$, José A. Oliveira $^{(\mathrm{e})}$ \\ (a),(b),(c),(d),(e) 4710-057, PORTUGAL \\ University of Minho \\ ALGORITMI Research Centre \\ (a) $\underline{\text { antonio.vieira@dps.uminho.pt, }},{ }^{\text {(b) }}$ lsd@dps.uminho.pt ${ }^{(\mathrm{c})}$ maribel@dsi.uminho.pt, ${ }^{(\mathrm{d})}$ gui@dps.uminho.pt, \\ ${ }^{(\mathrm{e})}$ zan@dps.uminho.pt
}

\begin{abstract}
Freeware and open source simulation software can be of great relevant when applying simulation in companies that do not possess the required monetary resources to invest in traditional commercial software, since these can be unaffordable Even so, there is a lack of papers that contribute to literature with a comparison of opensource and freeware simulation tools. Furthermore, such existing papers fail to establish a proper assessment of these type of tools. In this regard, this paper proposes a study in which several freeware and open source discrete-event general purpose simulation tools were selected and compared, in order to propose a ranking based on the tools' popularity, considering several criteria. For this purpose, 30 criteria were used to assess the score of each tool, leading to a podium composed by SimPy, JSim and JaamSim. Further conclusion and future work are discussed in the last section.
\end{abstract}

Keywords: Discrete-Event Simulation, Freeware, Open source, ranking, comparison, review.

\section{INTRODUCTION}

Discrete-event Simulation (DES), or just simulation, as many times is referred by other authors, is a technique used to run models on computers that represent systems being analyzed (A. A. C. Vieira et al. 2017, 2018). Furthermore, DES deals with stochastic behaviors, uncertainty, thus being appropriate to deal with complex systems that cannot be efficiently and effectively dealt by alternative approaches, e.g. analytical or mathematical models (Park et al. 2010). DES can be used for many objectives and the literature on studies using it is vast. With simulation, users can: study different components of a system and their interactions, communicate better with stakeholders involved in the problem, study alternatives without incurring in unnecessary costs or danger, solve complex problems, help in decision-making, and others (Fowler and Rose 2004; A. Vieira et al. 2014; António Vieira et al. 2014). Usually, modelers make use of commercial simulation software, such as Arena, Simio, ProModel, FlexSim,
WITNESS, PlantSimulation, AnyLogic and others (A. Vieira et al. 2015, 2016). However, while it is true that these tools have helped modelers in adopting and using DES, providing features for modelling, debugging and experimentation, it is also true that such software often are expensive, which many times are prohibitive for some companies, potentially leading to the abandonment of DES

For the above-exposed reason, freeware and open source simulation tools can be viewed as a solution to implement DES, in specific cases. Open source software is defined by Google as "software for which the original source code is made freely available and may be redistributed and modified" ("Google" 2019). In its turn, Google defines freeware as: "software that is available free of charge" ("Google" 2019). As can be seen, these are two types of software that usually do not entail costs to modelers. In fact, because of this, many times these two concepts are confuse.

There are several simulation freeware and open source tools available on the internet and there are also some studies that compare some of these tools. For instance, Dagkakis and Heavey (2016) considered 44 open source in their study. In this scenario of such large tools' offer, it becomes very hard and non-conclusive to perform a consistent experiment based on features. In fact, most of scientific works related to tools comparison analyze only a small set of features and ultimately avoiding a final judgment, due to the subjectivity of such task.

It is in the light of this that this paper proposes a ranking of the most popular freeware and open source simulation software. "Popularity" was the way that the authors found to overcome the mentioned difficulties. In this sense, choosing a popular simulation tool may bring benefits in two different perspectives:

- If you are with a company, it is easier to find simulation specialists with know-how on a popular tool;

- If you are a simulation specialist, it is easier to find companies working with a popular tool; 
Notwithstanding, popularity should not be solely used to select simulation tools. If this was the case, new ones, would never be used. Therefore, popularity may be seen as a significant factor to be used in conjunction with other criteria, such as features comparison.

In this regard, next section addresses the literature review conducted for this study. In its turn, section 3 described the methodology followed to select the tools used in the study and the criteria used to rank them. Section 4 focuses in explaining how the results are obtained, while section 5 shows the obtained classification. Last section presents the main conclusions withdrawn.

\section{LITERATURE REVIEW}

Several studies exist that compare discrete-event simulation software. For instance, regarding commercial tools' comparison, Hlupic (1999) compared a set of tools, distinguishing between users of software for educational purpose and users in industry. The same author (2000) presented a survey on the use of simulation software for academic and industrial users, which was conducted to discover how users were satisfied with the software and in which ways it could be improved.

Similarly, Abu-Taieh et al. (2007) reviewed 56 simulation tools to find answers for several aspects, such as: modelling approach, reporting features, programming language used, type of animation, simulation approach (i.e. discrete-event, dynamic continuous, etc.) and others.

In its turn, Jadrić et al. (2014) compared some simulation tools by developing the same considered model in the considered tools. Thereafter, the authors compared them, according to specified subjective and objective indicators.

Klingstam and Gullander (1999) outlined most used simulation tools in manufacturing engineering and Computer-Aided Production Engineering. The authors discussed most important features to consider when selecting the most appropriated software.

All these review papers or comparison studies, however, fail to make a judgement, or to somehow rank the considered tools. In this regard, Dias et al. (2007), Dias et al. (2011) and Dias et al. (2016) achieved this by ranking selected discrete-event simulation commercial software according to their "popularity", or presence in several fields, such as social networks, academic digital libraries and many others.

The mentioned studies compared commercial tools, by considering some criteria. However, in the case of open source or freeware simulation tools, there is a lack of such studies, to the best of the authors' knowledge. In fact, and corroborating what was stated by Byrne et al. (2012) there are limited papers considering open source or freeware simulation tools. Moreover, and a fortiori, existing studies fail to rank the considered tools.

\section{METHODOLOGY}

The methodology followed for this study is adapted from the works of Dias et al. (2007), Dias et al. (2011) and Dias et al. (2016). The main changes are related to the natural difference between commercial software and freeware and open source software, which is the existence of a vendor. Furthermore, some parameters have been removed or added along the years, because they either cease to be relevant, or become relevant, respectively.

This methodology can be divided in 3 groups. The first concerns with obtaining the list of tools that will be used on the ranking. In its turn, the second consists in defining the set of criteria to be used on the study, whilst the last group is related to obtaining the results for each defined criterion. Lastly, it should be stressed that this ranking only considered discrete-event simulation tools that are general purpose.

\subsection{Tools Selection}

The selection of tools used the following 2 main sources of information:

- Internet sources, such as: Informs ("Informs" 2019), Eurosis (Eurosis. 2019), Wikipedia ("Wikipedia" 2019);

- Available literature, e.g.: Dagkakis and Heavey (2016), King and Harrison (2013) and others.

Whilst the authors also had their own knowledge which allowed them to identify some of these tools, it should be noted that there were no cases of tools identified by own knowledge that could not be identified by the previous identified sources.

\subsection{Defined Criteria}

For this study, 30 criteria were considered. These can be grouped in the following 6 criteria groups:

- C1: Number of papers published in Winter Simulation Conference (world's largest simulation conference) that refer the simulation tool at hand;

- C2: Number of papers published in digital libraries (Scopus, Science Direct and Google Scholar) that refer to a simulation tool;

- C3: Number of results obtained by searching for the tool at hand in a social network (either Youtube, Facebook, Linkedin, Twitter or Google Plus);

- C4: Number of results obtained by searching for the tool in Google;

- C5: Analysis of the growth evolution of the results obtained in Google for a given tool;

- C6: Number of times a specific tool has been referred in a comparison paper, or a paper that considers several freeware or open source simulation tools;

- C7: Checking if the tool has a web site to disseminate it. 


\subsection{Obtaining Results}

The number of occurrences of a search query may vary from units to several millions. The sum of all of them together leads to irrelevant factors mixed with absorbent ones. To reduce this impact of different orders of magnitude, the use of mathematical functions was studied, in order to "control" big numbers, albeit keeping the relative differences between them. In this regard, square and cubic root, natural and ten base logarithms were the evaluated possibilities. Table 1 shows the values of the parameters' factors adjusted and the corresponding original raw values.

Table 1: Possible Functions to Factors Adjustment.

\begin{tabular}{|c|c|c|c|c|}
\hline & $\wedge 1 / 2$ & $\wedge 1 / 3$ & LN & LOG10 \\
\hline 1000000 & 1000 & 100 & 14 & 6 \\
\hline 100000 & 316 & 46 & 12 & 5 \\
\hline 10000 & 100 & 22 & 9 & 4 \\
\hline 1000 & 32 & 10 & 7 & 3 \\
\hline 100 & 10 & 5 & 5 & 2 \\
\hline 10 & 3 & 2 & 2 & 1 \\
\hline 1 & 1 & 1 & 0 & 0 \\
\hline
\end{tabular}

As can be seen, cubic root function considers small and big numbers adequately. Thus, it was used in this study. The use of a cubic root of a number in place of the number itself, is the same as comparing the volume of cubes, using only the value of their width.

\section{RESULTS ANALYSIS}

The results obtained for this study will be discussed in this section, for each of the defined criteria groups (see section 3). Figure 1 shows the results obtained for WSC (Winter Simulation Conference).

\begin{tabular}{|c|c|c|c|}
\hline \multirow{3}{*}{$\begin{array}{c}\text { DES Freeware } \\
\text { Tools } \\
\text { Weight }\end{array}$} & \multicolumn{3}{|c|}{ 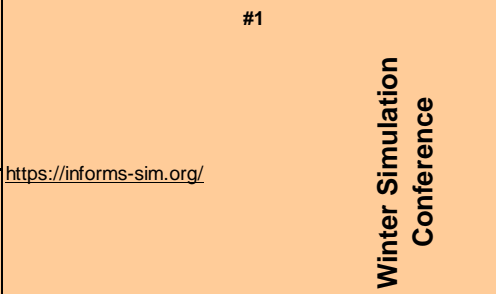 } \\
\hline & & 3 & \\
\hline & Search String & $\begin{array}{c}\text { Cubic Root } \\
\text { Results }\end{array}$ & $\begin{array}{c}\text { Raw } \\
\text { Results }\end{array}$ \\
\hline $\mathrm{C}++_{+}$Sim & "C++Sim" & 5,7 & 7 \\
\hline cloudes & |"cloudes" & 4,3 & 3 \\
\hline CSIM & "CSIM" "simulation" "C" "discrete" & 9,8 & 35 \\
\hline DESMO-J & "DESMO-J" & 6,9 & 12 \\
\hline DEUS & "DEUS" "Discrete Event Universal Simulator" & 4,3 & 3 \\
\hline FreeSML & "FreeSML" & 4,3 & 3 \\
\hline JaamSim & "JaamSim" & 6,0 & 8 \\
\hline jadesim & |"jadesim" & 0,0 & 0 \\
\hline japrosim & "japrosim" & 3,8 & 2 \\
\hline javaSim & "javaSim" & 8,0 & 19 \\
\hline JSIM & "JSIM" & 9,5 & 32 \\
\hline khronos DES & "khronos DES" & 0,0 & 0 \\
\hline sharpsim & "sharpsim" & 3,0 & 1 \\
\hline SIM.JS & "SIM.JS" & 0,0 & 0 \\
\hline sim4edu OESjs & "sim4edu OESjs" & 0,0 & 0 \\
\hline SimJ & "simj" & 3,0 & 1 \\
\hline simjava & "simjava" & 7,7 & 17 \\
\hline simkit & "simkit" & 11,5 & 56 \\
\hline simmer & "simmer" "simulation" "R" "discrete" & 0,0 & 0 \\
\hline SimPy & "SimPy" & 8,7 & 24 \\
\hline SSJ & "ssj" "stochastic" "simulation" "java" & 9,0 & 27 \\
\hline Tortuga & "Tortuga" & 4,3 & 3 \\
\hline Yetisim & "Yetisim" & 0,0 & 0 \\
\hline
\end{tabular}

Figure 1: Factor values for WSC
The column "Raw Results" gives the number of results obtained by searching for the "search strings" column values in the WSC website (https://informs-sim.org/). At this point, the cubic root mathematical function is applied and multiplied by the weight factor ( 3 in this case), in order to obtain "Factor value" column values.

As can be seen, SimKit was the tool that obtained more results. It should also be noted that there are 6 tools that obtained 0 results. Figure 2 illustrates the values obtained for the second criteria (see section 3 ).

\begin{tabular}{|c|c|c|c|}
\hline DES Freeware & 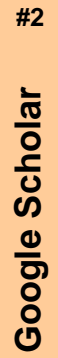 & 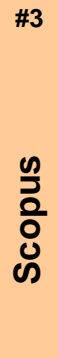 & 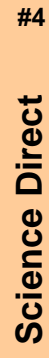 \\
\hline C++Sim & 3,3 & 2,7 & 2,4 \\
\hline cloudes & 5,3 & 1,8 & 0,0 \\
\hline CSIM & 12,2 & 1,9 & 4,8 \\
\hline DESMO-J & 6,7 & 2,4 & 1,9 \\
\hline DEUS & 1,0 & 1,0 & 2,4 \\
\hline FreeSML & 2,0 & 1,0 & 0,0 \\
\hline JaamSim & 3,4 & 1,6 & 1,3 \\
\hline jadesim & 1,9 & 0,0 & 0,0 \\
\hline japrosim & 2,6 & 1,9 & 0,0 \\
\hline javaSim & 8,2 & 2,2 & 3,6 \\
\hline JSIM & 8,8 & 2,3 & 3,6 \\
\hline khronos DES & 1,0 & 0,0 & 0,0 \\
\hline sharpsim & 2,4 & 1,3 & 1,0 \\
\hline SIM.JS & 0,0 & 0,0 & 1,0 \\
\hline sim4edu OESjs & 0,0 & 0,0 & 0,0 \\
\hline SimJ & 7,8 & 1,3 & 1,6 \\
\hline simjava & 10,6 & 2,6 & 3,6 \\
\hline simkit & 9,1 & 2,7 & 3,5 \\
\hline simmer & 1,0 & 1,8 & 5,1 \\
\hline SimPy & 8,9 & 2,6 & 3,9 \\
\hline SSJ & 5,9 & 1,4 & 1,9 \\
\hline Tortuga & 4,1 & 0,0 & 0,0 \\
\hline Yetisim & 1,4 & 1,0 & 0,0 \\
\hline
\end{tabular}

Figure 2: Factor values for Google Scholar, Scopus and Science Direct

The first thing to consider is that for this set of criteria, the weight 1 was used, contrarily to the previous criterion. Regarding the obtained results, the tools with most results are SimPy, SimKit, CSIM and SimJava, whilst SIM.JS, sim4edu, Khronos DES and Jadesim were the ones that obtained less results. Figure 3 shows the results obtained for the social networks criteria (see section 3 ). 


\begin{tabular}{|c|c|c|c|c|c|}
\hline DES Freeware & 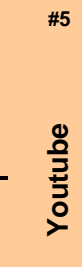 & 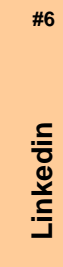 & 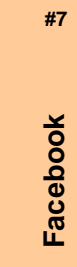 & 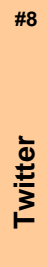 & 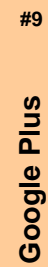 \\
\hline C++Sim & 0,0 & 1,3 & 0,0 & 0,0 & 0,0 \\
\hline cloudes & 2,6 & 2,2 & 0,0 & 1,4 & 0,0 \\
\hline CSIM & 1,0 & 3,4 & 0,0 & 0,0 & 0,0 \\
\hline DESMO-J & 1,7 & 1,6 & 1,0 & 0,0 & 0,0 \\
\hline DEUS & 0,0 & 1,0 & 1,0 & 0,0 & 0,0 \\
\hline FreeSML & 0,0 & 0,0 & 0,0 & 0,0 & 0,0 \\
\hline JaamSim & 5,4 & 3,2 & 1,0 & 1,3 & 1,7 \\
\hline jadesim & 0,0 & 0,0 & 0,0 & 0,0 & 0,0 \\
\hline japrosim & 0,0 & 0,0 & 0,0 & 0,0 & 0,0 \\
\hline javaSim & 0,0 & 1,6 & 0,0 & 0,0 & 0,0 \\
\hline JSIM & 1,9 & 2,7 & 0,0 & 0,0 & 1,0 \\
\hline khronos DES & 0,0 & 0,0 & 0,0 & 0,0 & 0,0 \\
\hline sharpsim & 0,0 & 1,0 & 1,3 & 0,0 & 0,0 \\
\hline SIM.JS & 1,3 & 2,7 & 0,0 & 0,0 & 0,0 \\
\hline sim4edu OESjs & 0,0 & 0,0 & 0,0 & 0,0 & 0,0 \\
\hline SimJ & 0,0 & 1,6 & 0,0 & 0,0 & 0,0 \\
\hline simjava & 1,6 & 2,2 & $\square 1,3$ & 0,0 & 0,0 \\
\hline simkit & 1,4 & 3,3 & 1,4 & 0,0 & 0,0 \\
\hline simmer & 2,0 & 1,4 & 0,0 & 1,3 & 1,4 \\
\hline SimPy & 7,5 & 5,3 & 1,7 & 1,6 & 2,1 \\
\hline SSJ & 0,0 & 0,0 & 0,0 & 0,0 & 0,0 \\
\hline Tortuga & 0,0 & 2,0 & 4,0 & 0,0 & 0,0 \\
\hline Yetisim & 0,0 & 1,0 & 0,0 & 1,3 & 0,0 \\
\hline
\end{tabular}

Figure 3: Factor values for Youtube, Linkedin, Facebook, Twitter and Google Plus

The first thing to notice is that there are many tools without presence in the selected social networks, e.g., SSJ, Sim4edu, Japrosim, FreeSML, Khronos DES, Jadesim and others. These networks are useful for users, for instance, to help members in interacting with the tools. On the other hand, there are only 2 tools without 0 in any of the selected social networks: SimPy and JaamSim. Figure 4 shows the results obtained for the fourth and fifth criteria, i.e., Google results and the growth evolution of the Google results.
For the 2 sets of criteria represented in Figure 4, different weight values were assigned, in order to give more importance to more recent values. In this regard, the raw results are shows in a red (less results) to green (more results) scale. As can be see, all tools are increasing their results along the years. Furthermore, JSIM, Simmer and JaamSim were the tools with most Google results, whilst JSIM, SimPy and CSIM were the tools with most Google results growth. It is also interesting to note that, from the analyzed tools none seems to be decreasing their Google Results, indicating an overall growth of open source and freeware simulation tools. Figure 5 shows the results obtained for the sixth set of criteria (see section3). Regarding this criterion, the following papers were considered:

- $\quad$ Page et al. (1997);

- $\quad$ Sawhney and Mund (1998);

- $\quad$ Sawhney et al. (1999);

- $\quad$ Miller et al. (2000);

- Sawhney et al. (2000);

- L'Ecuyer et al. (2002);

- Weatherly and Page (2004);

- $\quad$ L'Ecuyer and Buist (2005);

- $\quad$ King and Harrison (2013);

- $\quad$ Peixoto et al (2017);

- Dagkakis and Heavey (2016).

By considering Figure 5, it should be noted that, for each selected paper, a weight of 0.5 was assigned. The titles of the chosen papers can be seen in the heading of this figure. SimKit, SimJava, JavaSim and JSIM were the tools with better results, whilst Cloudes, simmer, sim4edu, SimJ, FreeSML and Khronos DES obtained 0 in this criterion. Figure 6 shows the results obtained for the last considered criterion (see section 3).

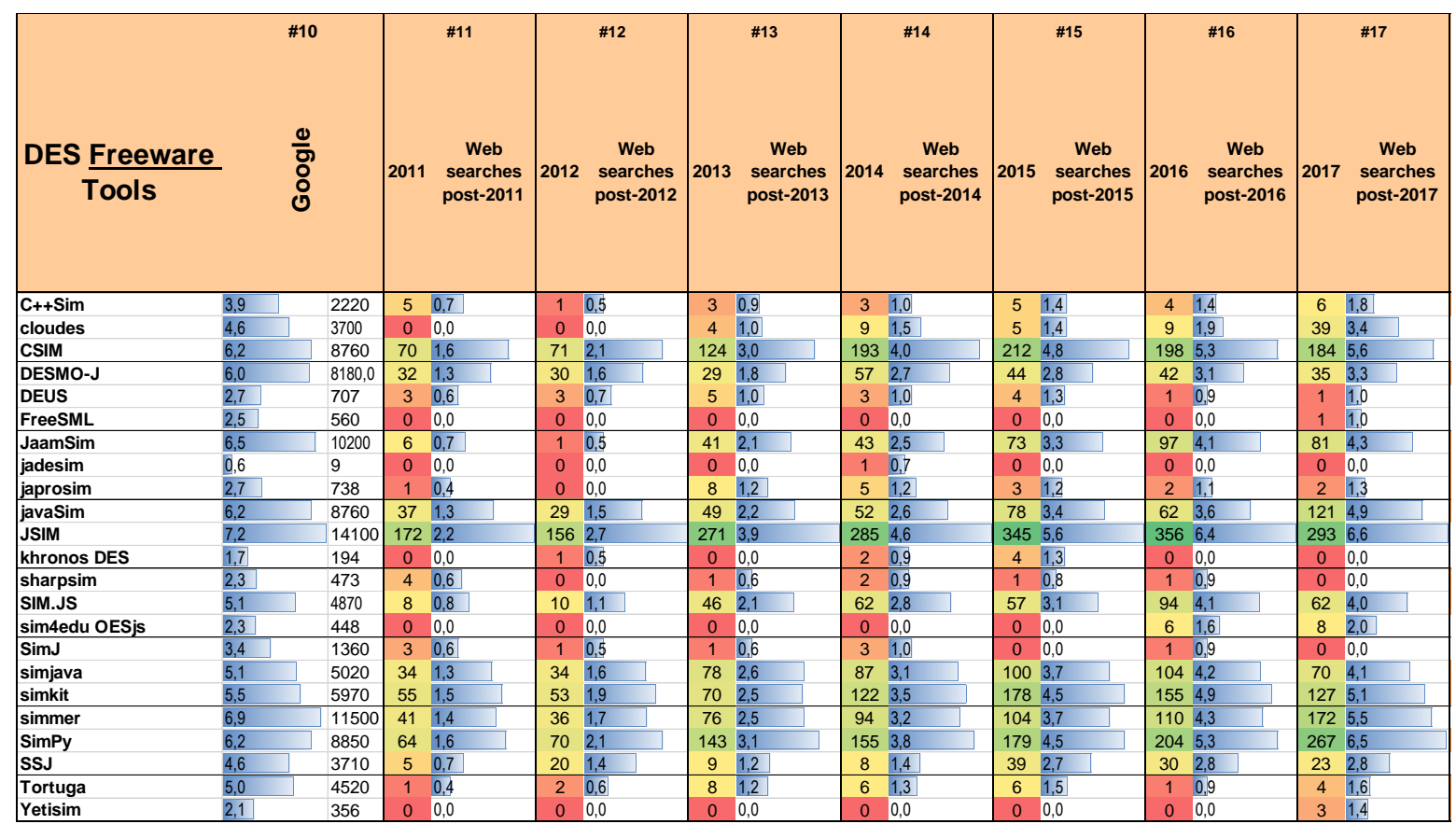

Figure 4: Factor values obtained for Google and the growth evolution of Google factor values 


\begin{tabular}{|c|c|c|c|c|c|c|c|c|c|c|c|c|c|}
\hline DES Freeware $\frac{\text { Tools }}{\text { Tols }}$ & \begin{tabular}{|l}
\multicolumn{1}{c}{$\# 18$} \\
A review of \\
open \\
source \\
discrete \\
event \\
simulation \\
software \\
for \\
operations \\
research
\end{tabular} & $\begin{array}{l}\quad \text { \#19 } \\
\text { The JSIM } \\
\text { web-based } \\
\text { simulation } \\
\text { environment }\end{array}$ & $\begin{array}{l}\quad \text { \#20 } \\
\text { Open- } \\
\text { source } \\
\text { simulation } \\
\text { software } \\
\text { jaamsim }\end{array}$ & $\begin{array}{l}\quad \text { \#21 } \\
\text { Free and } \\
\text { open- } \\
\text { source } \\
\text { simulation } \\
\text { software } \\
\text { "ururau" }\end{array}$ & $\begin{array}{l}\quad \text { \#22 } \\
\text { Web-Based } \\
\text { Simulation } \\
\text { in Simjava } \\
\text { Using } \\
\text { Remote } \\
\text { Method } \\
\text { Invocation }\end{array}$ & \begin{tabular}{l}
\multicolumn{1}{c}{ \#23 } \\
Ssj: a \\
framework \\
for \\
stochastic \\
simulation in \\
java
\end{tabular} & $\begin{array}{l}\quad \text { \#24 } \\
\text { Efficient } \\
\text { process } \\
\text { interaction } \\
\text { simulation in } \\
\text { n java: } \\
\text { implementin } \\
\text { g co- } \\
\text { routines } \\
\text { within a } \\
\text { single java } \\
\text { thread }\end{array}$ & $\begin{array}{l}\quad \text { \#25 } \\
\text { Simulation } \\
\text { in Java with } \\
\text { SSJ }\end{array}$ & $\begin{array}{l}\quad \text { \#26 } \\
\text { simulation } \\
\text { based } \\
\text { construction } \\
\text { manageme } \\
\text { nt learning } \\
\text { system }\end{array}$ & $\begin{array}{l}\quad \text { \#27 } \\
\text { Javabeans- } \\
\text { based } \\
\text { framework } \\
\text { for } \\
\text { construction } \\
\text { simulation }\end{array}$ & $\begin{array}{l}\quad \text { \#28 } \\
\text { Java-based } \\
\text { simulation } \\
\text { of } \\
\text { construction } \\
\text { processes } \\
\text { using silk }\end{array}$ & & 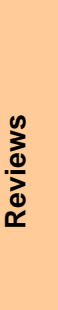 \\
\hline $\mathrm{C}++_{+} \mathrm{Sim}$ & & & & & & & & & & & & 3 & 7,9 \\
\hline cloudes & & & & & & & & & & & & 0 & 0,0 \\
\hline CSIM & & & & & & & & & & & & 2 & 6,9 \\
\hline DESMO-J & & & & & & & & & & & & 4 & 8,7 \\
\hline DEUS & & & & & & & & & & & & 1 & 5,5 \\
\hline FreeSML & & & & & & & & & & & & 0 & 0,0 \\
\hline JaamSim & & & & & & & & & & & & 2 & 6,9 \\
\hline jadesim & & & & & & & & & & & & 1 & 5,5 \\
\hline japrosim & & & & & & & & & & & & 1 & 5,5 \\
\hline javaSim & & & & & & & & & & & & 8 & 11,0 \\
\hline JSIM & & & & & & & & & & & & 7 & 10,5 \\
\hline khronos DES & & & & & & & & & & & & 0 & 0,0 \\
\hline sharpsim & & & & & & & & & & & & 1 & 5,5 \\
\hline SIM.JS & & & & & & & & & & & & 1 & 5,5 \\
\hline sim4edu OESjs & & & & & & & & & & & & 0 & 0,0 \\
\hline SimJ & & & & & & & & & & & & 0 & 0,0 \\
\hline simjava & & & & & & & & & & & & 8 & 11,0 \\
\hline simkit & & & & & & & & & & & & 10 & 11,8 \\
\hline simmer & & & & & & & & & & & & 0 & 0,0 \\
\hline SimPy & & & & & & & & & & & & 1 & 5,5 \\
\hline SSJ & & & & & & & & & & & & 3 & 7,9 \\
\hline Tortuga & & & & & & & & & & & & 3 & 7,9 \\
\hline Yetisim & & & & & & & & & & & & 1 & 5,5 \\
\hline
\end{tabular}

Figure 5: Factor values for selected papers

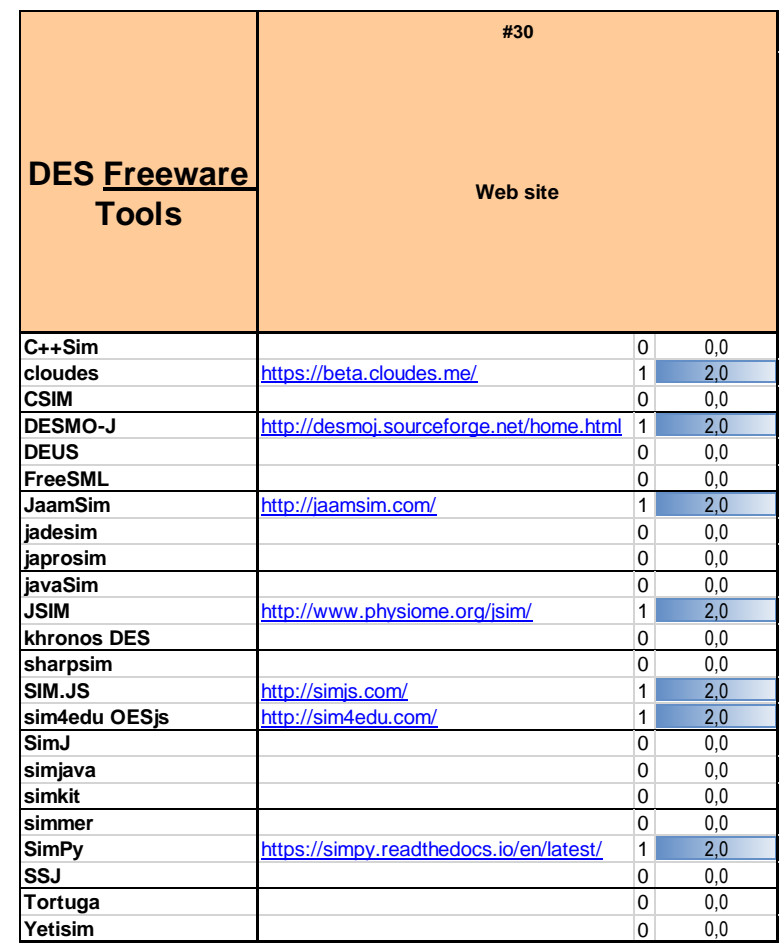

Figure 6: Factor values for the tools' web site assessment criterion

For this criterion a weight of 2 was considered. Furthermore, tools that have web pages for several types of content, therein including content related to a specific tool (e.g., web page of a university's department which developed a tool, includes reference to a tool in its web page), were not considered. As the figure suggests, only 7 tools were found that match the established restrictions for the web page assessment.

\section{RANKING THE SIMULATION TOOLS}

This section describes the process of obtaining the final ranking of each assessed tool. In this regard, the steps can be summarized as follows:

- The first step is to sum the values $[\mathrm{S}]$ of the criteria of each group (see section 3 ).

- Thereafter, to neutralize different categories scales, the resulting values were normalized. Thus, the upper ceiling [C] value was calculated. This corresponds to the sum of the average of the sums $[\mathrm{A}(\mathrm{S})]$ with the standard deviation of the sums $[\mathrm{D}(\mathrm{S})]$, the latter being multiplied by $1.5[\mathrm{C}=\mathrm{A}(\mathrm{S})+1.5 * \mathrm{D}(\mathrm{S})]$.

- Each criteria group's score is then calculated, by dividing its sum by $\mathrm{C}[\mathrm{S} / \mathrm{C}]$, and multiplying it by 10 , truncating the maximum value to 10 . As result, all obtained criteria's scores are between 0 and 10 .

The obtained values can be seen in Figure 8. The same figure also shows the final score obtained for each tool, which is obtained by calculating a pondered average between the obtained values and the corresponding weights to the criteria. To assign the subjective weights to the sets of criteria the authors formed the following 3 groups:

- Presence in internet, as a whole. (fourth and fifth sets of criteria in section 3, or WWW and Growth in Figure 8); 
- presence in academy, in particular (first, second and sixth sets of criteria in section 3, or WSC, Docs and Reviews in Figure 8);

- $\quad$ presence in social networks, in particular (third and seventh sets of criteria in section 3 , or Social and Web site in Figure 8).

For each of these 3 groups, 4 weights points were assigned, as described in Figure 8, with the final results specified in the same figure. In its turn, Figure 7 shows the scores grouped by each set of criteria.

With the ranking completed, it can be seen that SimPy was the tool placed in the first position, followed very closely by JSIM, with the podium being finalized with
JaamSim. A reference should also be made to Cloudes, which, to the best of the authors' knowledge, is the tool that allows users to work on the cloud that is best placed in this ranking. As indicated by Figure 7 this classification of Cloudes concerns with its lack of presence in academy, namely: in WSC, review papers and selected digital libraries (Google Scholar, Scopus and Science Direct). Khronos DES and Jadesim were tools ranked in the last places. An honorable mention can also be done to other tools that were also considered for this study but did not enter the final ranking, as they did not obtain the minimum score. Those tools including: Simjulia, DSOL, Salabim and XGDESK.

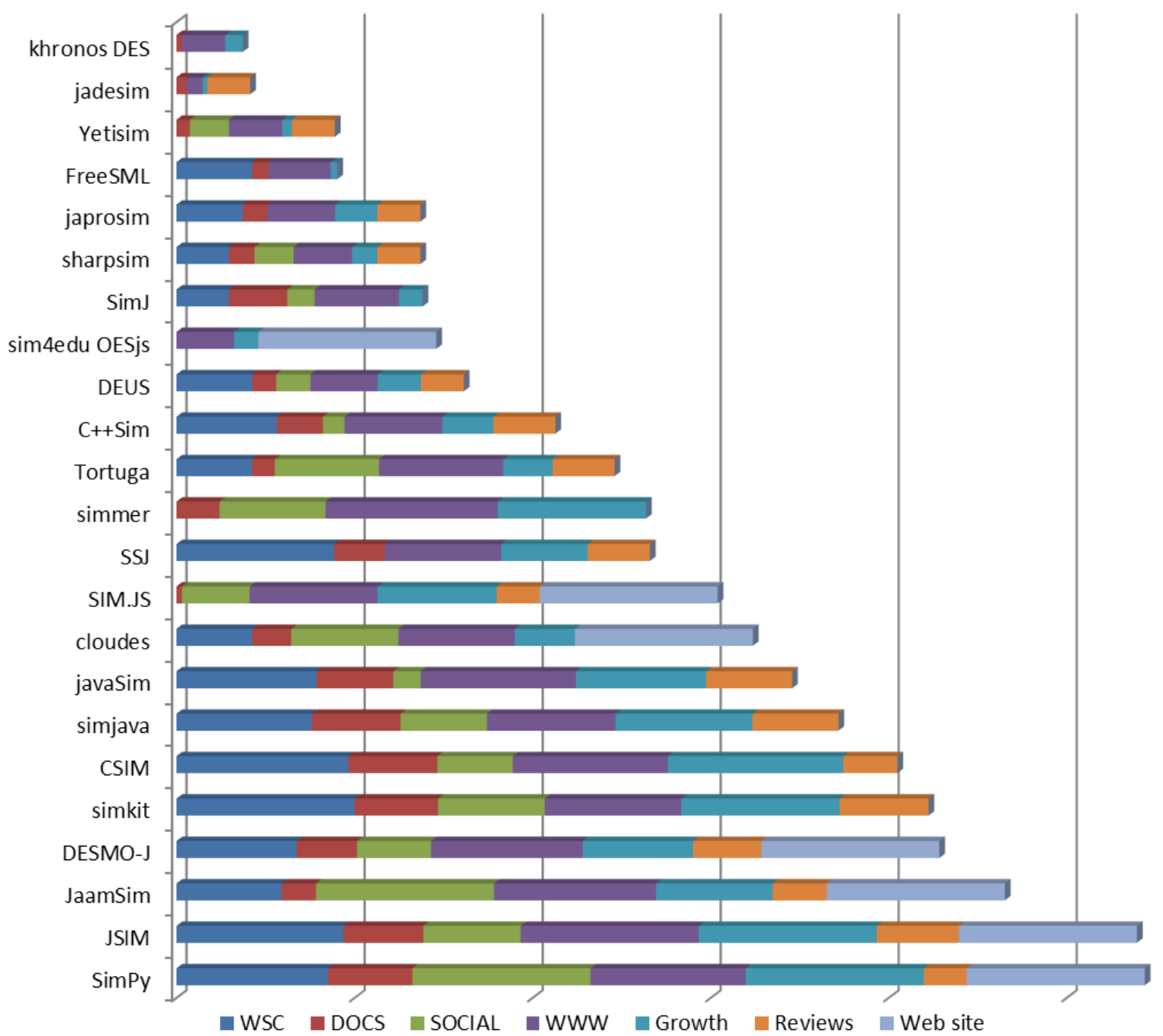

Figure 7: Scores grouped by set of defined criteria 


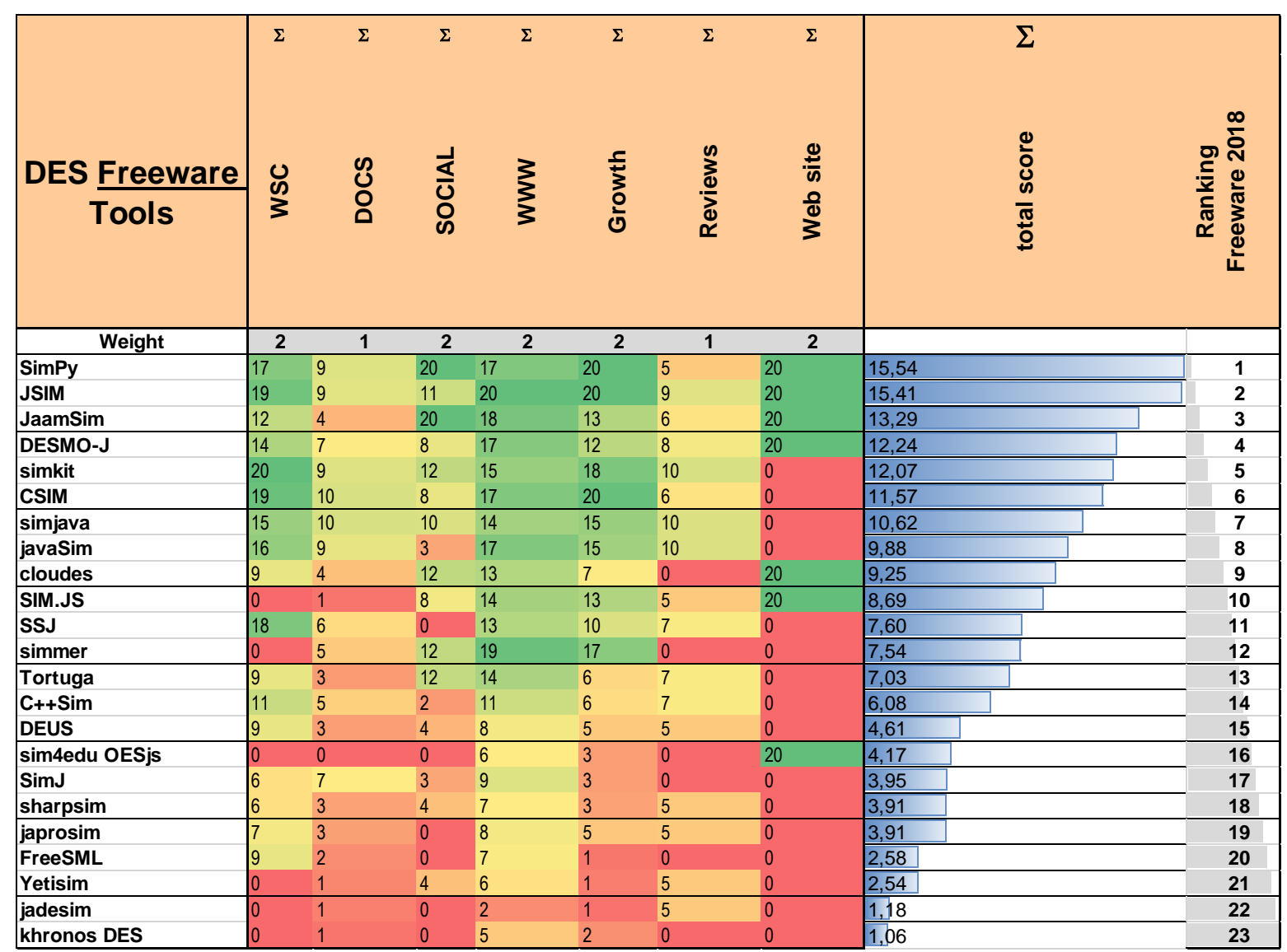

Figure 8: Final scores obtained for each set of criteria and for each tool

\section{CONCLUSIONS}

This paper proposed to rank several open source or freeware simulation tools, according to their popularity. More specifically, according to their presence on academia content, social networks and internet as a whole. The authors used this approach since existing studies that propose to compare freeware and open source simulation tools, ultimately fail to make a judgment or to establish a proper ranking between them. For this purpose, 30 criteria were established and divided among 7 groups, in order to use them to assess each tool. Moreover, the cubic root of the obtained values for each criterion was used, in order to mitigate the different scales of the obtained results. In addition, different weights were assigned to each criterion. Although different weights were used to classify the chosen criteria, the authors believe to have proposed a trustworthy ranking of "popular" open source or freeware simulation tools. Lastly, it should be noted that only tools that address discrete-event simulation and are general purpose, were considered.

After having finalized the study, it is possible to see that SimPy was ranked in first place, closely followed by JSIM, with JaamSim finalizing the podium. Screenshots of some of the considered tools can be consulted in the appendix section. The results obtained by the authors are subject to changes, whether as a consequence of the academic or industry environments. Thus, this study should be regularly updated, by considering new criteria and likewise by pondering on what weight values make sense in the light of more recent trends (e.g., nowadays Facebook may be a relevant social network for simulation users, but in the future, it may cease to be). By establishing a comparison between the results for WSC (L. M. S. Dias et al. 2016) with the same criteria for this ranking, it is possible to see that the former registered 409 results, which is around $86 \%$ more than the maximum value in freeware and open source tools (SimKit with 56 results). This suggests that, despite the utility of open source and freeware simulation software, their use is still limited.

A last note should be made to emphasize that the authors do not seek to promote freeware or open source tools, or any in specific. In addition, the authors do not want to discourage the use of commercial tools. Rather, this paper recognizes the role and position of freeware and open source simulation tools in the DES community and tried to contribute to literature with a study that assessed and ranked these tools.

\section{ACKNOWLEDGMENTS}

This work has been supported by FCT - Fundação para a Ciência e Tecnologia within the Project Scope: UID/CEC/00319/2019 and by the Doctoral scholarship PDE/BDE/114566/2016 funded by FCT, the Portuguese Ministry of Science, Technology and Higher Education, through national funds, and co-financed by the European Social Fund (ESF) through the Operational Programme for Human Capital (POCH). 


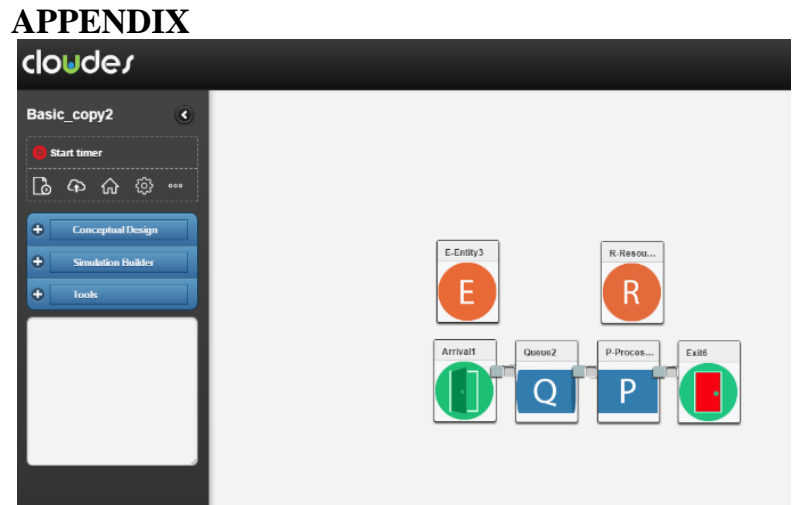

Figure 9: Cloudes screenshot

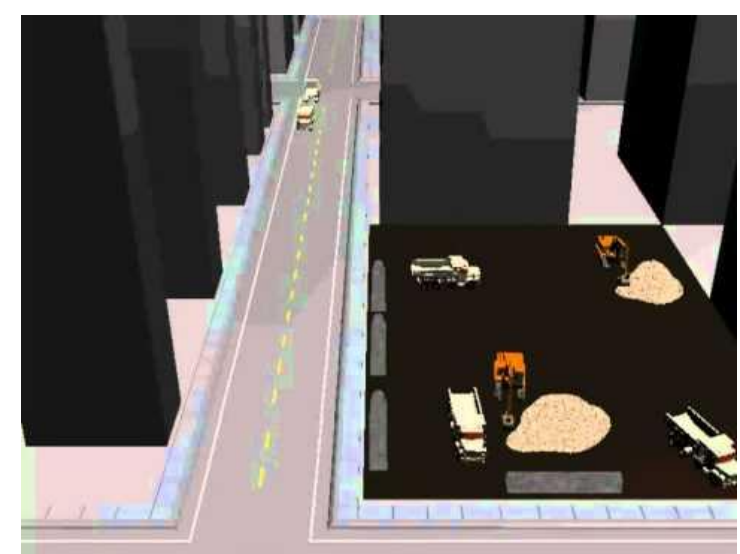

Figure 10: DESMO-J (3D view) screenshot

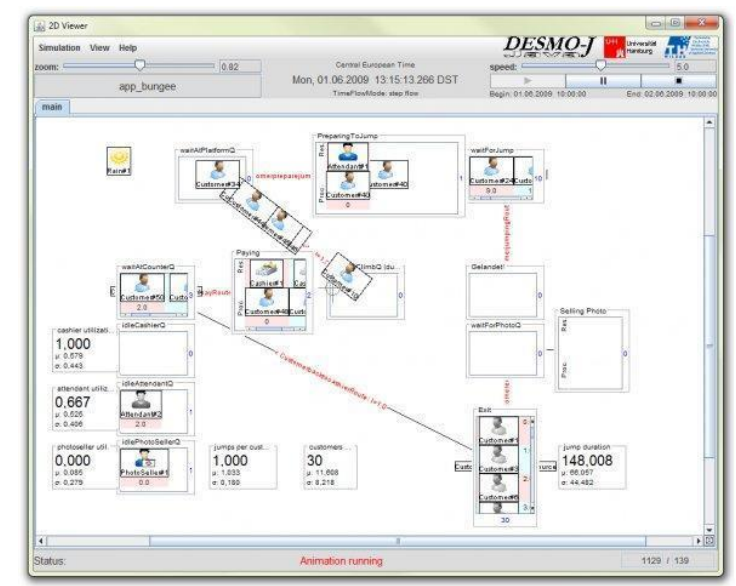

Figure 11: DESMO-J (2D view) screenshot

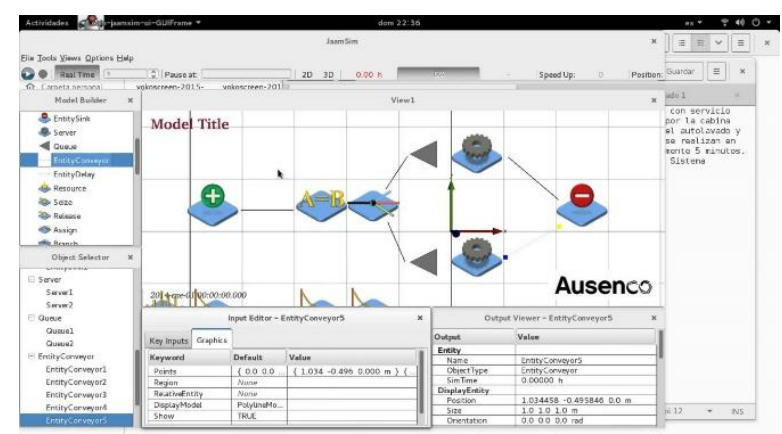

Figure 12: JaamSim screenshot

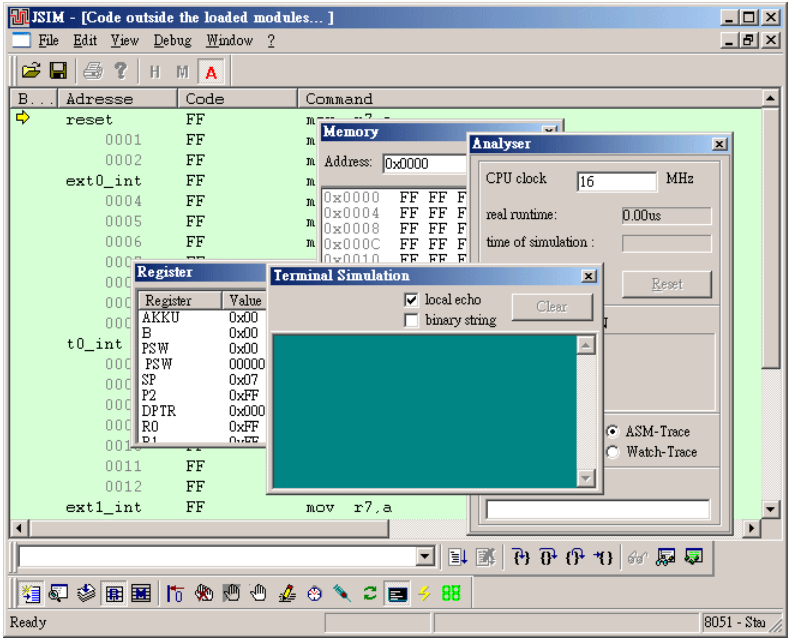

Figure 13: JSIM screenshot

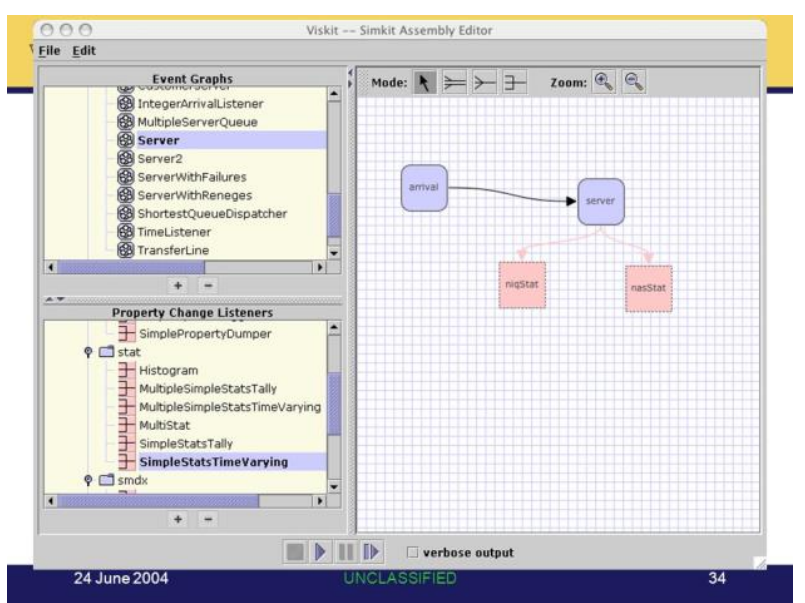

Figure 14: SimKit

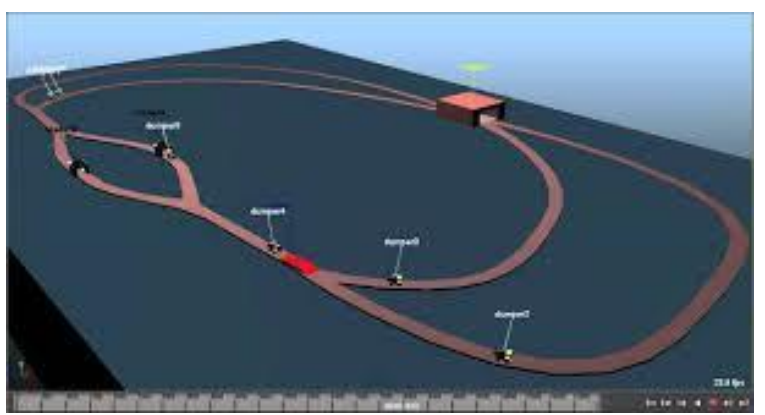

Figure 15: SimPy screenshot

\section{REFERENCES}

Abu-Taieh, E M O, and A A R El Sheikh. 2007. "Commercial Simulation Packages: A Comparative Study." International Journal of Simulation: Systems, Science and Technology 8 (2): 66-76.

Byrne, N, P Liston, J Geraghty, and P Young. 2012. "The Potential Role of Open Source Discrete Event Simulation Software in the Manufacturing Sector." In , 117-26.

Dagkakis, G, and C Heavey. 2016. "A Review of Open Source Discrete Event Simulation Software for Operations Research." Journal of Simulation 10 (3): 193-206. https://doi.org/10.1057/jos.2015.9. 
Dias, L., G. Pereira, and G. Rodrigues. 2007. "A Shortlist of the Most Popular Discrete Simulation Tools." In Simulation News Europe, 17,33-36.

Dias, L., G. Pereira, P. Vik, and J. Oliveira. 2011. "Discrete Simulation Tools Ranking: A Commercial Software Packages Comparison Based on Popularity." In Industrial Simulation Conference. Venice, Italy, 6-8.

Dias, Luis M. S., Antonio A. C. Vieira, Guilherme A. B. Pereira, and Jose A. Oliveira. 2016. "Discrete Simulation Software Ranking — A Top List of the Worldwide Most Popular and Used Tools." In 2016 Winter Simulation Conference (WSC), 1060-71.

IEEE. https://doi.org/10.1109/WSC.2016.7822165.

Eurosis. 2019. "Simulation and Gaming Software Development Tools and Languages." https://www.eurosis.org/cms/?q=node/61.

Fowler, J W, and O Rose. 2004. "Grand Challenges in Modeling and Simulation of Complex Manufacturing Systems." Simulation 80 (9): 46976. https://doi.org/10.1177/0037549704044324.

“Google." 2019. 2019. https://www.google.com.

Hlupic, V, and R J Paul. 1999. "Guidelines for Selection of Manufacturing Simulation Software." IIE Transactions $31 \quad$ (1): 21-29. https://doi.org/10.1023/A:1007568516643.

Hlupic, Vlatka. 2000. "Simulation Software: An Operational Research Society Survey of Academic and Industrial Users." In Winter Simulation Conference Proceedings, 2:1676-83.

"Informs." 2019. 2019. https://pubsonline.informs.org/magazine/ormstoday.

Jadrić, Mario, Maja Ćukušić, and Antonia Bralić. 2014. "Comparison of Discrete Event Simulation Tools in an Academic Environment." Croatian Operational Research Review 5 (2): 203-19. https://doi.org/10.17535/crorr.2014.0008.

King, D. H., and Harvey S. Harrison. 2013. "OpenSource Simulation Software \&\#x201C;JaamSim\&\#x201D;" In 2013 Winter Simulations Conference (WSC), 2163-71. IEEE. https://doi.org/10.1109/WSC.2013.6721593.

Klingstam, Pär, and Per Gullander. 1999. "Overview of Simulation Tools for Computer-Aided Production Engineering." Computers in Industry 38 (2): 17386. 3615(98)00117-1.

L'Ecuyer, P., and E. Buist. 2005. "Simulation in Java with SSJ." In Proceedings of the Winter Simulation Conference, 2005., 611-20. IEEE. https://doi.org/10.1109/WSC.2005.1574301.

L'Ecuyer, P L, Lakhdar Meliani, and Jean Vaucher. 2002. "SSJ: A Framework for Stochastic Simulation in Java." In Simulation Conference, 2002. Proceedings of the Winter, 1:234-42. IEEE.

Miller, John A, Andrew F Seila, and Xuewei Xiang. 2000. "The JSIM Web-Based Simulation Environment." Future Generation Computer $\begin{array}{lll}\text { Systems } & 17 & (2):\end{array}$ https://doi.org/10.1016/S0167-739X(99)00108-9.

Page, Ernest H, Robert L Moose Jr., and Sean P Griffin. 1997. "Web-Based Simulation in Simjava Using Remote Method Invocation." In , 468-74.

Park, Hyeong-Tae, Jong-Geun Kwak, Gi-Nam Wang, and Sang C. Park. 2010. "Plant Model Generation for PLC Simulation." International Journal of Production Research 48 (5): 1517-29. https://doi.org/10.1080/00207540802577961.

Peixoto, Túlio Almeida, João José de Assis Rangel, Ítalo de Oliveira Matias, Fábio Freitas da Silva, and Eder Reis Tavares. 2017. "Ururau: A Free and Open-Source Discrete Event Simulation Software." Journal of Simulation 11 (4): 303-21. https://doi.org/10.1057/s41273-016-0038-5.

Sawhney, Anil, Hemant Deshpande, and Andre Mund. 2000. "JavaBeans-Based Framework for Construction Simulation.” In , 2:1919-25.

Sawhney, Anil, Jayachandran Manickam, Andre Mund, and Jennifer Marble. 1999. "Java-Based Simulation of Construction Processes Using Silk.” In , 2:985-91.

Sawhney, Anil, and Andre Mund. 1998. "Simulation Based Construction Management Learning System.” In , 2:1319-24.

Vieira, A., L.S. Dias, G.A.B. Pereira, J.A. Oliveira, M.S. Carvalho, and P. Martins. 2015. "Using Simio to Automatically Create 3d Warehouses and Compare Different Storage Strategies." FME Transactions 43 https://doi.org/10.5937/fmet1504335V.

Vieira, A., L.S. Dias, G.B. Pereira, and J.A. Oliveira. 2014. Micro Simulation to Evaluate the Impact of Introducing Pre-Signals in Traffic Intersections. Lecture Notes in Computer Science (Including Subseries Lecture Notes in Artificial Intelligence and Lecture Notes in Bioinformatics). Vol. 8584 LNCS. https://doi.org/10.1007/978-3-319-091532_54.

Vieira, A., L.S. Dias, G.B. Pereira, J.A. Oliveira, M.S. Carvalho, and P. Martins. 2016. "Automatic Simulation Models Generation of Warehouses with Milk Runs and Pickers." In 28th European Modeling and Simulation Symposium, EMSS 2016. Winner of the Best Paper Award, 231-41.

Vieira, A.A.C., L.M.S. Dias, G.A.B. Pereira, and J.A. Oliveira. 2017. Agent-Based Simulation to Assess the Performance of Intersections with PreSignals: Comparison with Roundabouts. Lecture Notes in Computer Science (Including Subseries Lecture Notes in Artificial Intelligence and Lecture Notes in Bioinformatics). Vol. 10572 LNCS. https://doi.org/10.1007/978-3-319-684963_36.

Vieira, A A C, L M S Dias, G A B Pereira, J A Oliveira, M Do Sameiro Carvalho, and P Martins. 2018. "Simulation Model Generation for Warehouse Management: Case Study to Test Different Storage Strategies." International Journal of 
Simulation and Process Modelling 13 (4): $324-$ 36. https://doi.org/10.1504/IJSPM.2018.093761.

Vieira, António, Luís M. S. Dias, Guilherme Pereira, and José A. Oliveira. 2014. "Comparison of SIMIO and ARENA Simulation Tools." In 12th Annual Industrial Simulation Conference (ISC2014), 5-13.

Weatherly, R M, and E H Page. 2004. "Efficient Process Interaction Simulation in Java: Implementing Co-Routines within a Single Java Thread." In , 2:1437-43.

"Wikipedia." https://en.wikipedia.org/wiki/List_of_discrete_ev ent_simulation_software.

\section{AUTHORS BIOGRAPHY}

António A.C. Vieira is an Invited Assistant Professor and Researcher of the ALGORITMI Research Centre, University of Minho, Portugal. He holds a MSc degree in Systems Engineering at the University of Minho. He is making his doctoral studies in Advanced Engineering Systems for Industry at the University of Minho, in partnership with Bosch Car Multimedia Braga. His research interests include Modelling and Simulation, Logistics and Transportation, and Big Data. His email address is antonio.vieira@dps.uminho.pt.

Luís M.S. Dias is an Auxiliar Professor and Researcher of the ALGORITMI Research Centre, University of Minho, Portugal. He holds a PhD degree in Production and Systems Engineering from the University of Minho, Portugal. His research interests include Simulation, Systems Performance, Operational Research and Systems Visual Modeling. His email address is 1sd@dps.uminho.pt.

Maribel Y. Santos is an Associate Professor at the Department of Information Systems and Researcher of the ALGORITMI Research Centre, University of Minho (UMinho), in Portugal. She received the Aggregated title (Habilitation) in Information Systems and Technologies (IST) from UMinho in 2012 and a $\mathrm{PhD}$ in Information Systems and Technologies from UMinho in 2001. Her research interests include Business Intelligence and Analytics, Big Data and (Big) Data Warehousing. Her email address is maribel@dsi.uminho.pt.

Guilherme A.B. Pereira is an Associate Professor and Researcher of the ALGORITMI Research Centre, University of Minho (UMinho), in Portugal. He holds a $\mathrm{PhD}$ degree in Manufacturing and Mechanical Engineering from the University of Birmingham, UK. His research interests include Operational Research and Simulation. Currently he is Pro-Rector of the University of Minho. His email address is gui@dps.uminho.pt.
José A. Oliveira is an Auxiliar Professor and Researcher of the ALGORITMI Research Centre, University of Minho (UMinho), in Portugal. He holds a PhD degree in Production and Systems Engineering from the University of Minho, Portugal. His research interests include Optimization with Heuristic Methods in Systems Engineering. His email address is zan@dps.uminho.pt. 